\title{
Experimental and numerical analysis of concrete slabs prestressed with composite reinforcement
}

\author{
R. Sovják ${ }^{1}$, P. Máca ${ }^{1}$, P. Konvalinka ${ }^{1}$ \& J. L. Vítek ${ }^{2}$ \\ ${ }^{I}$ Experimental Centre, Faculty of Civil Engineering, \\ Czech Technical University in Prague, Czech Republic \\ ${ }^{2}$ Department of Concrete and Masonry Structures, \\ Faculty of Civil Engineering, Czech Technical University in Prague, \\ Czech Republic
}

\begin{abstract}
The behaviour of concrete slabs prestressed with glass fibre reinforced polymer (GFRP) composite bars is investigated in this paper. The main advantage of GFRP bars is their high strength/self-weight ratio. On the other hand, Young's modulus is very low compared to steel reinforcement, which is the main cause for unacceptable deflections. To eliminate such deflections and to utilize the high tensile strength of GFRP bars it is very useful to pretension the bars. During the experimental work a set of three concrete slabs $4.5 \mathrm{~m}$ long was casted. Each slab was prestressed with four GFRP bars. The slabs were subjected to four points bending. Each specimen was subjected to ten tow-load cycles and afterwards loaded until failure. Deflection under each loading point and in the middle of the beam span was recorded. Moreover, stress at the lower and upper surface was measured. The experimental procedure was modelled numerically in finite element nonlinear software. Brick elements were used for meshing and the full Newton-Raphson method was used for calculation. Special bond slip-law (GFRP-concrete) is involved based on the experimental results of pull-out tests. A stress-strain diagram and the stress and crack development were plotted. The experimental and numerical results show a statistically important relationship. A large deflection typical for GFRP reinforced slabs is observed, as well as very early crack propagation. The serviceability limit state (SLS) is exceeded much earlier than bar rupture is observed. For this reason, it is recommended that the design of GFRP reinforced structures is governed by SLS criteria.

Keywords: composites, concrete, GFRP, numerical modelling, prestressing.
\end{abstract}




\section{Introduction}

The service lifetime of reinforced concrete structures is in many cases determined by the durability of the reinforcement itself. For this reason much attention is being paid to improving the resistance of the reinforcement to aggressive environments. Because steel bars are currently the most used type of reinforcement, several options of improving its corrosion resistance have been developed. One way is to improve the properties of the concrete itself by decreasing its permeability, increasing concrete cover and waterproofing the concrete. The other way is to use epoxy coated bars. However, it has been proven that none of these measures or their combination can eliminate the longterm risk of steel corrosion [1]. The ultimate way to provide corrosion resistance is to use bars made from stainless steel, but this solution is highly expensive and not always possible. Therefore, in recent years non-metallic reinforcement has gained a great deal of interest from many researchers.

Fibre-reinforced polymer (FRP) reinforcement is by nature corrosion resistant. Therefore it can be successfully used in highly corrosive environments such as bridge decks, off-shore structures and slabs in chemical factories where high corrosion resistance is required. Furthermore, FRP reinforcement has other great properties such as magnetic transparency, thermal non-conductivity and generally higher tensile strength than steel.

The behaviour of FRP bars, however, is different than that of steel and is highly dependent on the type of fibre and the production process. FRP reinforcement is linear-elastic up to failure and its elastic modulus is typically lower than that of steel. For instance FRP bars that are reinforced with glass fibres (GFRP) have typically a modulus of elasticity of 15 to $25 \%$ of steel. Furthermore, there are FRP bars with many different surface textures available on the market and every producer makes a unique type of bar. For this reason the design of structures reinforced with FRP bars must be approached with maximal caution.

As mentioned above the low elastic modulus is the biggest issue that needs to be considered when designing concrete structures that are reinforced with GFRP bars. The main problem is that the overall stiffness of GFRP reinforced concrete member decreases significantly after the concrete cracks in the tension zone. From the cracked section analysis [2] it can be easily calculated that deflection and crack widths will be much larger for concrete member reinforced with GFRP bars compared to that reinforced with steel.

One of the methods how to eliminate unacceptable deflections on serviceability limit state (SLS) is to pretension the GFRP reinforcing bars. This paper describes both experimental and numerical analysis of concrete slabs that are reinforced with GFRP pre-tensioned bars. Many researchers reported [3, 4, 10] that pretensioning of the GFRP bars help to decrease deflections and crack widths.

\subsection{Research significance}

Composite reinforcement is relatively new material and it has a potential to be widely applied in structures where special properties such as corrosion resistance 
or magnetic wave transparency are required. In fact, FRP reinforcement has been implemented in several structures all over the world. However, composite materials, including FRP, are very dependent on the production technology and process. Therefore every producer creates a unique product which is very similar to other products but not exactly the same - it is like with finger prints.

FRP bars consist of two main components - fibres and matrix. Every component can be chosen accordingly to the specific needs of the customer. This gives the much needed adjustability and variability of building materials. Moreover the final characteristics of the entire rod will be different than characteristics that would be obtained by simple summation of properties of fibres and matrix. This effect is called synergism [5]. Based on these facts it is very important to conduct extensive research in this specific area in order to describe, clarify and completely understand behaviour of concrete structures reinforced with FRP reinforcement which is available locally.

\section{Material characteristics}

Before the loading tests were performed exact mechanical characteristics of materials used during this research were determined. This is very important as it helps to eliminate the number of variables. Elastic modulus, modulus of rupture (MOR) and compressive strength of concrete were measured. Cylinders were used for the modulus of elasticity measurement and $150 \mathrm{~mm}$ cubes were used for the ultimate compressive strength determination. The average results of these measurements are summarized in Table 1.

Furthermore, basic properties of GFRP were determined such as modulus of elasticity and axial coefficient of thermal expansion. The tensile strength was determined by the producer and was not checked by the researchers. These material characteristics are compared with standard steel properties in Table 2.

Table 1: $\quad$ Material characteristics of used concrete.

\begin{tabular}{|l|l|l|}
\hline & Size of test specimen & Average value \\
\hline Compressive strength & cubes $150 \mathrm{~mm}$ & $36,55 \mathrm{MPa}$ \\
\hline MOR & beams $100 \times 100 \times 400 \mathrm{~mm}$ & $6,08 \mathrm{MPa}$ \\
\hline Modulus of elasticity & cylinders $\varnothing 150 \times 400 \mathrm{~mm}$ & $30,8 \mathrm{GPa}$ \\
\hline
\end{tabular}

Table 2: $\quad$ Material characteristics of GFRP bars in comparison with standard steel.

\begin{tabular}{|l|l|l|}
\hline & GFRP & Steel B500 \\
\hline Tensile strength [MPa] & 650 & 500 \\
\hline Modulus of elasticity [GPa] & 40 & 210 \\
\hline $\begin{array}{l}\text { Axial coefficient of thermal } \\
\text { expansion }\left[1 /{ }^{\circ} \mathrm{C}\right]\end{array}$ & $6 \mathrm{e}-06$ & $12 \mathrm{e}-06$ \\
\hline Stress-strain diagram & Linear-elastic & Bi-linear with hardening \\
\hline
\end{tabular}




\section{Experimental procedure}

Experimental work was done in laboratories of Experimental Centre in the faculty of Civil Engineering, Czech Technical University, Prague. Three slabs reinforced with prestressed GFRP bars were tested in four point bending test.

The slabs were $4.5 \mathrm{~m}$ long with a clear span of $4 \mathrm{~m}$. The loading points were approximately in thirds of the span. The setup of the experiment is shown in Figure 1 and the cross section of the slab is shown in Figure 2.

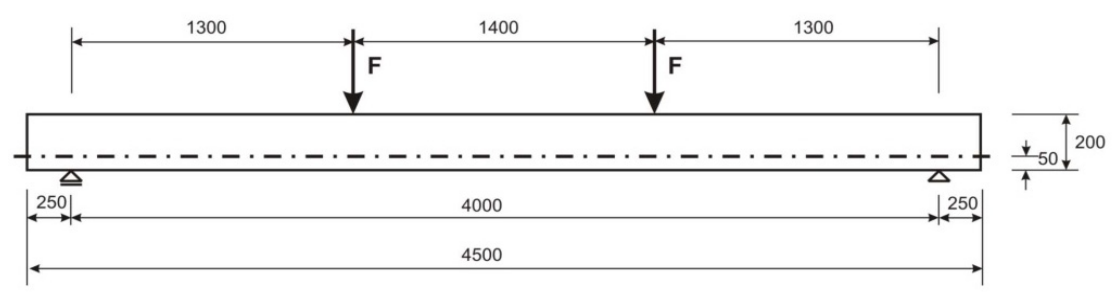

Figure 1: $\quad$ Slab dimensions.
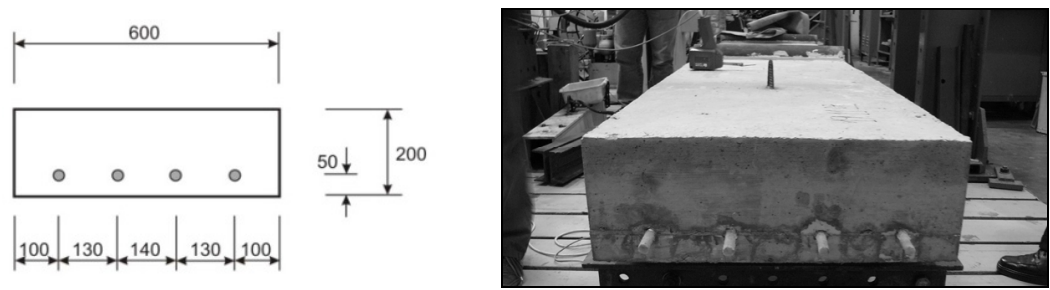

Figure 2: Cross-section.

Each slab was reinforced with four GFRP bars with diameter of $14 \mathrm{~mm}$. The bars were pretensioned to stress $215 \mathrm{MPa}$. This stress level corresponds to one third of the ultimate tensile strength of the bar as provided by the producer. At both ends of the slab three stirrups (at $50 \mathrm{~mm}$ centres) were inserted to provide reinforcement for the lateral stresses induced by the pre-tensioned bars. It can be seen in Table 1 that the concrete used to cast the slabs had average compressive strength of $36 \mathrm{MPa}$ and the concrete cover was $43 \mathrm{~mm}$.

\subsection{Pretensioning procedure}

The pretensioning procedure was relatively simple. A wooden mould was constructed on the floor of the lab and both stirrups and GFRP tendons were inserted inside. GFRP tendons were $6 \mathrm{~m}$ long with resin filled anchors at both ends. Anchors on one side of the mould were inserted into a fixed holder (Fig. 3) and on the other side the anchors were gripped into specially developed jacking mechanism. This mechanism consisted of anchor holder and a screw steel bar. During the pre-tensioning procedure a load transducer cell was attached to the 
end of the screw bar and the bar was tightened with a moment inducing wrench. This jacking mechanism used was similar to that presented in Fig. 3. (Note that Fig. 3 shows different experiment with 5 CFRP bars). When the tensile force measured by the load transducer reached $33 \mathrm{kN}$ which corresponds to stress $215 \mathrm{MPa}$ in the GFRP bar, the pretensioning procedure was finished. After that the screw bar was fixed in its position by a female screw.
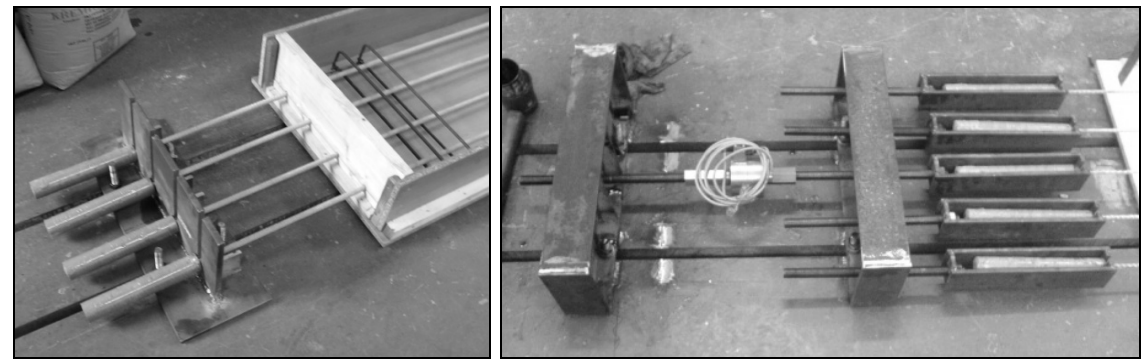

Figure 3: The passive end holder (on the right) and jacking mechanism (on the left).

\subsection{Loading}

After the GFRP tendons were pretensioned concrete was casted in the moulds and vibrated. Each slab was properly cured by moisturising its surface until testing. After 28 days from casting, the slabs were tested in four point bending. At the beginning of the experimental procedure each slab was loaded ten times to $30 \%$ of its calculated ultimate strength. This load level approximately corresponded to the SLS. After the ten cycles, the loading force was increased in constant force increments until failure. Deflections were measured with LVDT's at the middle of the span and under the loading points. Strain gauges were attached at the bottom and top of the slab.

\section{Numerical model}

To be able to simulate similar tests in the future and to successfully predict behaviour of GFRP reinforced members, numerical model in software called ATENA 3D was created. This software is commercially developed by Cervenka Consulting Ltd. and a version 3.3.2 was used in this research programme. ATENA is a three-dimensional nonlinear finite element program and it is primarily developed for reinforced concrete design.

The calculation was preformed with help of full Newton-Raphson method. This method was selected to match the experimental loading procedure. The basic principle of this method is to increase loading force in small increments since the problem is generally non-linear. Stiffness matrix is recalculated in every step and after each iteration. Additionally line-search can be added to the $\mathrm{N}-\mathrm{R}$ method in order to speed up the procedure when negligible nonlinearity is expected. This helps to decrease the number of iterations in every step significantly. 
Table 3: $\quad$ Equations for SBETA model.

\begin{tabular}{|l|l|}
\hline Parameter: & Formula: \\
\hline Cylinder strength & $f_{c}^{\prime}=-0.85 f_{c u}^{\prime}$ \\
\hline Tensile strength & $f_{t}^{\prime}=0.24 f_{c u}^{\prime \frac{2}{3}}$ \\
\hline Initial elastic modulus & $E_{c}=\left(6000-15.5 f_{c u}^{\prime}\right) \sqrt{f_{c u}^{\prime}}$ \\
\hline Poisson's ratio & $v=0.2$ \\
\hline Softening compression & $w_{d}=-0.0005 \mathrm{~mm}$ \\
\hline Type of tension softening & $1-$ exponential, based on $G_{F}$ \\
\hline Compressive strength in cracked concrete & $c=0.8$ \\
\hline Tension stiffening stress & $\sigma_{s t}=0$. \\
\hline Shear retention factor & variable \\
\hline Tension-compression function type & linear \\
\hline Fracture energy $G_{f}$ according to VOS 1983 & $G_{F}=0.000025 f_{t}^{\prime e f}[M N / m]$ \\
\hline Orientation factor for strain localization & $\gamma_{\max }=1.5$ \\
\hline
\end{tabular}

\subsection{Concrete}

Material characteristics of concrete has been determined according to the Constitutive SBETA model (CCSbetaMaterial) implemented in ATENA 3D [6]. Parameters were estimated according to the ultimate cubic strength.

\subsection{GFRP}

Based on the series of experiments [7] it was proved that linear-elastic behaviour is typical for glass based composites. Therefore linear-elastic model was chosen with characteristics showed in Table 2.

\subsection{Reinforcement bond model}

The basic property of the reinforcement bond model is the bond-slip relationship. This relationship defines the bond strength depending on the value of current slip between reinforcement and surrounding concrete so called bond-slip law [8].

GFRP reinforcement is specific by its surface coating therefore a special bond model was developed in order to describe concrete-GFRP interaction. During the previous experimental work [8] the slip of sand coated bars was measured. Similar bars were used in this experiment and therefore the slip values between bar and concrete (Fig. 5) were used in the ATENA reinforcement model.

\subsection{FE mesh}

The size and type of finite-element mesh has very important implications towards the numerical result. For this particular design linear elements were used with nodes only on their corners. The elements were cubic with a dimension of 


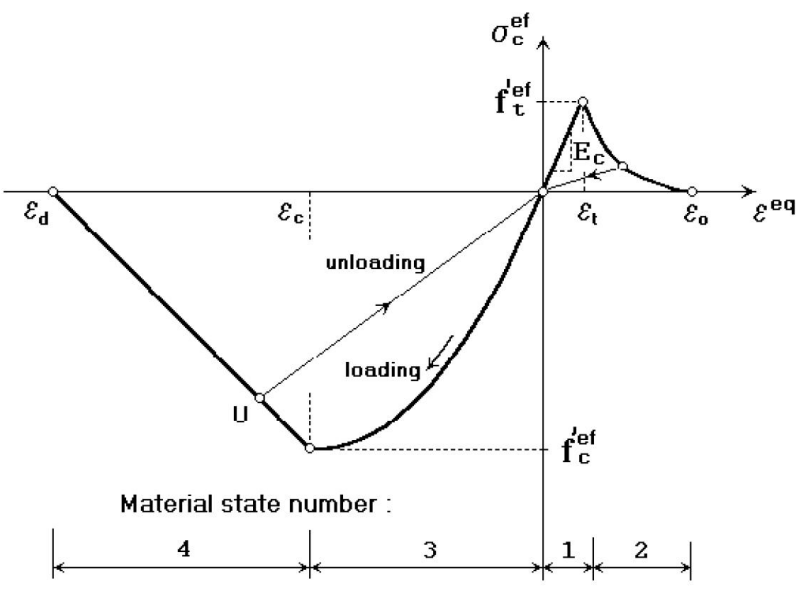

Figure 4: $\quad$ Stress-strain diagram for concrete.

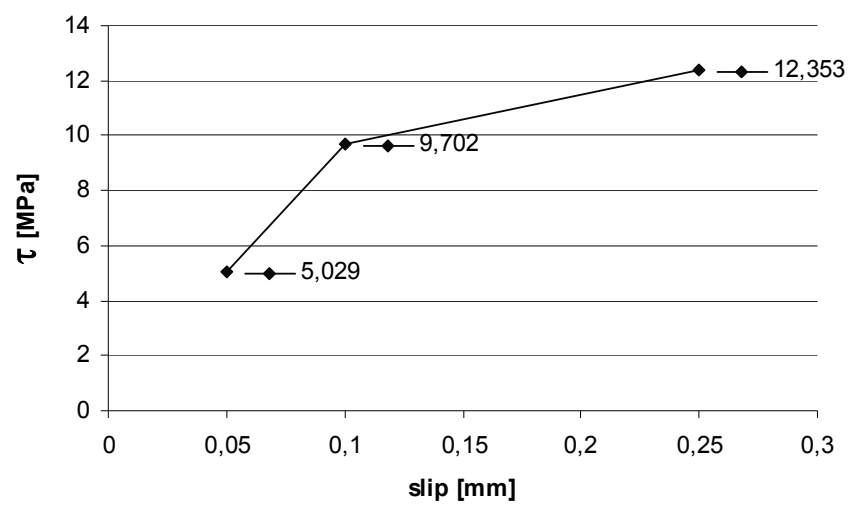

Figure 5: Bond-slip law.

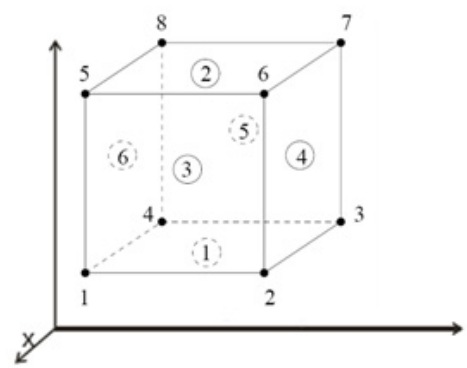

Figure 6: Finite element brick model with nodes only on the corners. 
$50 \mathrm{~mm}$. Such elements are referred to as bricks (Fig. 6). This mesh was generated using the mesh generator T3D which is integrated into the ATENA software.

Moreover, contact elements were implemented in order to cover interface between steel plates and concrete slab. Steel plates were used for a load distribution across the entire width of the concrete slab.

\subsection{Basic equations}

As mention before the solution method is non-linear and standard NewtonRaphson method is used. The principle of this method is in solving a matrix of nonlinear equations, which can be written as:

$$
k(\vec{p}) \Delta \vec{p}=\vec{q}-f(\vec{p}),
$$

where: $\vec{q}$ is the vector of total applied joint loads, $f(\vec{p})$ is the vector of internal joint forces, $\Delta(\vec{p})$ is the deformation increment due to loading increment, $\vec{p}$ are the deformations of structure prior to load increment, $K(\vec{p})$ is the stiffness matrix, relating loading increments to deformation increments.

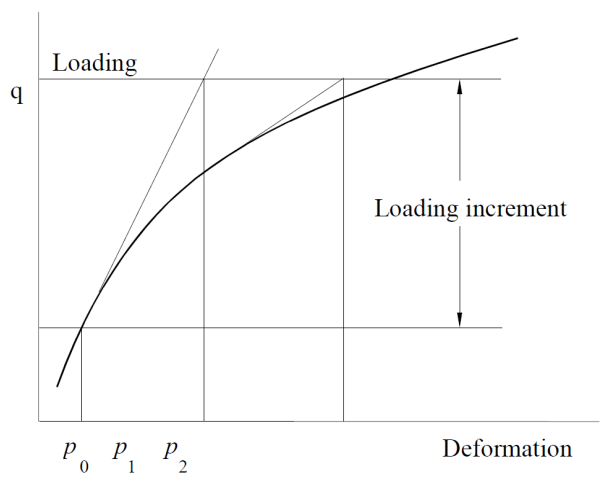

Figure 7: $\quad$ Full Newton-Raphson method.

The right hand side of eqn. (1) represents out-of-balance forces during a load increment. Generally, the stiffness matrix is deformation dependent, as a function of $p$, but this is usually neglected within a load increment in order to preserve linearity. In this case the stiffness matrix is calculated based on the value of $p$ pertaining to the level prior to the load increment. The set of equations (1) is nonlinear because of the non-linear properties of the internal forces:

$$
f(k \vec{p}) \neq k f(\vec{p})
$$


and nonlinearity in the stiffness matrix

$$
K(\vec{p}) \neq K(\vec{p}+\Delta \vec{p})
$$

where $k$ is an arbitrary constant.

The concept of solving a nonlinear set of equations by Full Newton-Raphson method is depicted in Figure 7.

\section{Results}

Stress-strain diagram of concrete members reinforced with GFRP bars is bilinear. First part so called un-cracked elastic is typical for small increments of deflection within rising bending moment. The second linear part is called cracked-elastic and it is expected that the tensile stress is carried solely by the reinforcement. Because the GFRP bar behaviour is linear-elastic the second part of stress-strain diagram of the slab is also liner-elastic.

As rather big deflections were observed during the experimental procedure (Fig. 8 and 9) it is evident that serviceability limit state will be limiting factor when designing concrete members with GFRP reinforcement.

Pre-stressing of GFRP tendons benefits from the high tensile strength of GFRP and performs significantly better in terms of deflection and crack development compared to non-prestressed elements. Figure 8 shows crack widths and stress field in the numerical model of the slab at collapse. Also failure of slab during the experimental part of the work is shown in Fig. 8. GFRP bars were pre-stressed up to $30 \%$ of their ultimate strength according to ACI 440.4 [10] recommendations. This corresponds to the force $33 \mathrm{kN}$ in every tendon.
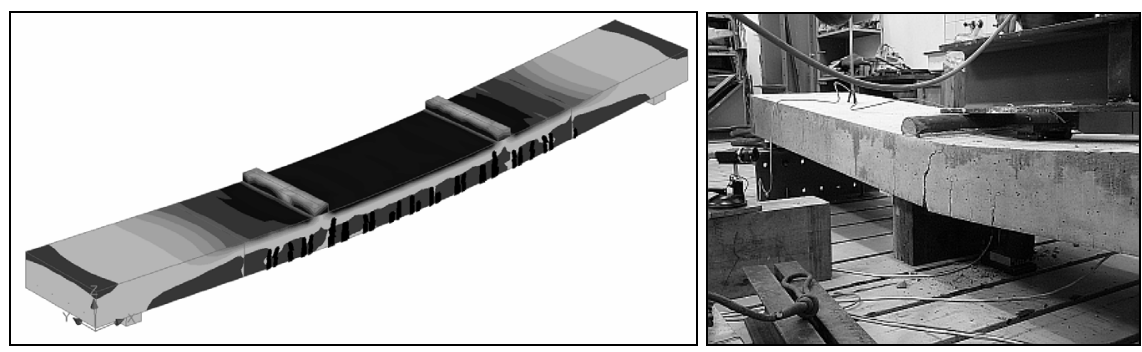

Figure 8: $\quad$ Stress field and crack formation at failure (numerical model) and slab failure (experimental model).

The correlation coefficient proved a very good relationship between numerical model and real structure as shown in Fig. 10. Therefore it is possible to predict behaviour of concrete structures with altered shape or even slightly different FRP reinforcement type. However, it is important to pay attention to input values and material relations that are inserted into the numerical model as the model is very sensitive. 

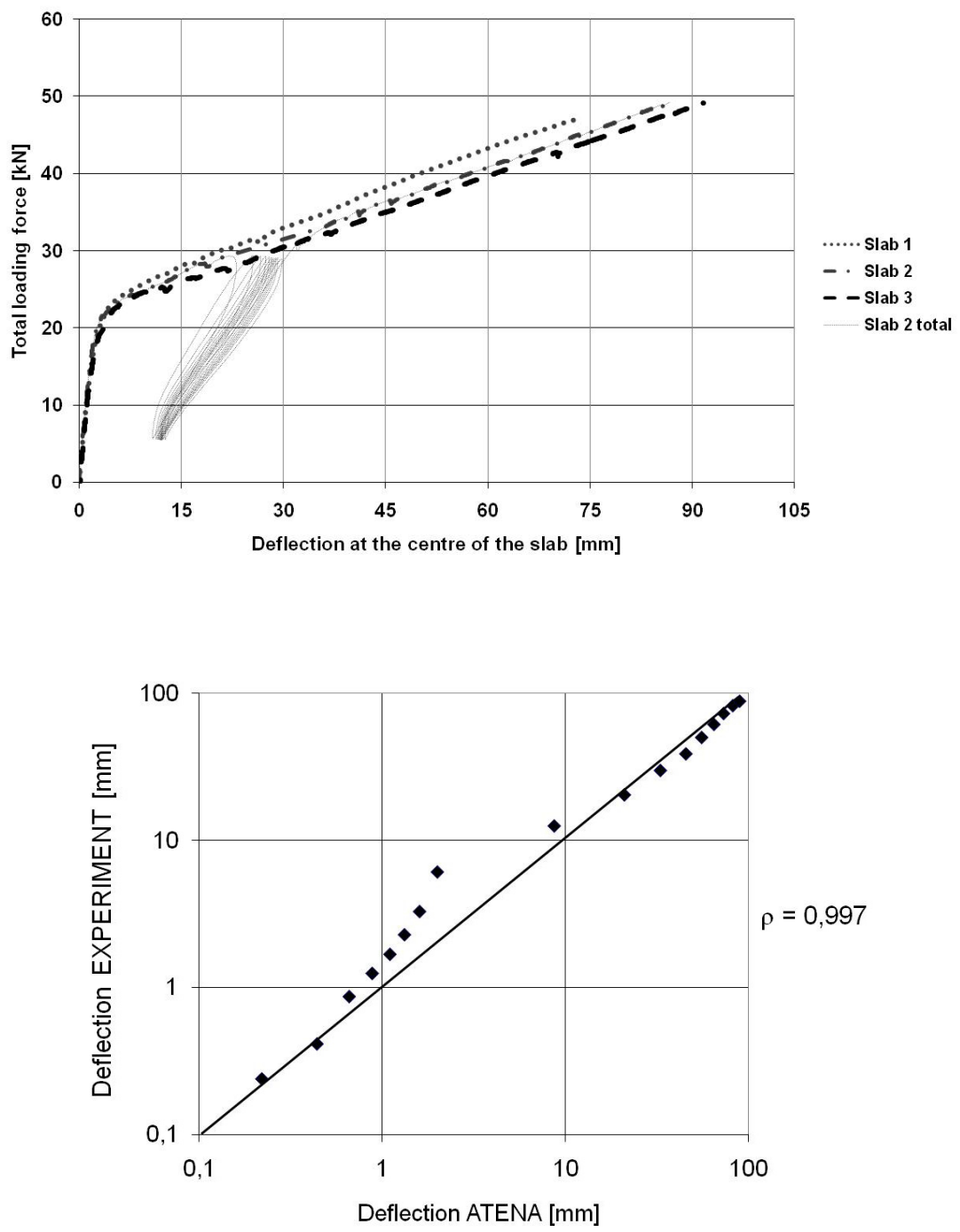

Figure 9: Load-deflection diagram.

Figure 10: Relationship between numerical and experimental values in logarithmic scale.

\section{Conclusions and further research}

High strength-weight ratio and corrosion resistance are characteristics that make GFRP an exceptional structural material. On the other hand, low modulus of elasticity causes bigger deflections and early crack development. Prestressing 
significantly enhance behaviour of concrete members with GFRP reinforcement. Specifically prestressing decreases deformations and therefore prevents early crack development. By pre-stressing the GFRP reinforcement is more utilized in tension and therefore the usage of prestressed GFRP is more economical.

Behaviour description of concrete members reinforced with FRP tendons should provide guidance for engineers and designers when using this new type of reinforcement. However, there is no design guide or code for FRP structures in the Czech Republic. Basic understanding of GFRP application in concrete prevents eventual problems and summarizes what to expect when dealing with GFRP as an internal reinforcement in concrete structures.

Numerical predictive model has been developed based on the experimental outcome in order to evaluate behaviour of other concrete members with different shapes or even slightly different FRP reinforcement.

Concrete structures for civil purposes are usually designed for fifty years lifespan, bridges even for hundred. This report is part of research that has shown so far how concrete structures reinforced with FRP bars behave under load. Nevertheless the long term behaviour of such structures is still not described very well and more research is needed in this area.

The researchers suggest conducting an experimental work focused on the permanently loaded elements as well as the high cycle fatigue test. These will be the next tasks on the field of fibre reinforced polymers.

\section{Acknowledgement}

This research has been supported by the Ministry of Education of the Czech Republic under the no. MSM6840770031.

\section{References}

[1] Mosley, C.P., Tureyen, A.K., Frosch R.J., (2008) Bond Strength of Nonmetallic Reinforcing Bars, ACI Structural Journal, Vol.105, no. 5.

[2] Procházka, J., Bradáč, J., Krátký, J., Filipová J., Hanzlová, H., (2003), Concrete Structures: Design according to the EUROCODE 2

[3] Burke, C.R., Dolan, C.W., (2001), Flexural design of prestressed concrete beams using FRP tendons, PCI J. 46, p.76-87.

[4] El-Hacha, R., (2005), Prestressing concrete structures with FRP tendons (ACI 440.4R-04), 1635-1642.

[5] Michna, Š., (2006), Composites materials

[6] Červenka, J., (2005), ATENA Program Documentation: Tutorial for Program ATENA 3D. [online], [seen 2008-05-13]. Available at: http://www.cervenka.cz/papers

[7] Sovják, R., Máca, P., Fornůsek, J., Konvalinka, P., Vítek, J., (2009), Determination of material characteristics of GFRP bar from nano to macro level, In: Workshop 2009, CTU in Prague

[8] Fornůsek, J., (2007), Bc. Thesis: Bond Between GFRP Bars and Concrete Depended on Bar's Surface 
94 Computational Methods and Experimental Measurements XIV

[9] Sovják, R., Konvalinka, P., Vítek, J., (2008), Concrete structures with nonmetallic reinforcement, In: Contributions to numerical and experimental investigation of building materials and structures, vol. 1, p. 73-76

[10] ACI 440.4R-03, (2003), Prestressing concrete structures with FRP tendons, American Concrete Institute, Farmington Hills, Mich.

[11] Červenka, V., Jendele, L., (2007), ATENA Theory, Part 1 